\section{Ice-age dust and sea salt}

SIR-Harvey ${ }^{1}$ has estimated the climatic effect of increased tropospheric aerosols during the last glacial maximum (LGM). Attributing to the present tropospheric aerosol a globally averaged optical depth, $\tau$, of 0.13 (at $550-\mathrm{nm}$ wavelength) and a 2-3-K surface cooling, Harvey rather more than doubles $\tau$ during the LGM and finds a further cooling of $2-3 \mathrm{~K}$.

The ice-core evidence he cites concerns only two aerosol components: continental dust, which is measured by the insoluble particles $\mathrm{Al}$ or $\mathrm{Ca}^{2+}$; and marine sea salt, which is measured by $\mathrm{Na}^{+}$. Together, dust and sea salt form the 'coarse mode', or supermicrometre, fraction of today's atmospheric aerosol, with sources, sinks and optical properties distinct from the fine, or submicrometre, mode.

Because these two modes vary independently in the atmosphere (which the icecore record itself dramatically confirms ${ }^{2}$ ), Harvey's modelling exercise properly constitutes an estimate of the LGM cooling resulting from dust and sea salt only, and should therefore have begun with an estimate of the optical depth due solely to the coarse mode, $\tau_{\text {coarse }}$, in the present-day climate. Note that the studies cited for confirmation of his control model were each concerned with the total tropospheric aerosol, not just the coarse mode fraction.

Early investigators (see ref. 3) recognized that the tropospheric aerosol mass is more or less evenly divided between primary particles, mainly dust and sea salt, and secondary particles (those produced in situ from gases), mostly sulphates. It was later demonstrated that these primary and secondary components have very different sizes ${ }^{2.5}$ and, consequently, very different solar extinction efficiencies ${ }^{6}$, the fine-mode sulphates being about six times more efficient per unit mass. Thus, a reasonable estimate, in agreement with limited direct observations, is that the coarse mode causes about 15 per cent of $\tau$. (It will cause an even smaller fraction of aerosol-induced cooling since larger particles scatter sunlight much more into the forward direction.)

Taking this estimate as uncertain by a factor of 2 and assuming that current $\tau$ falls somewhere between 0.1 and 0.2 (ref. 7), we can estimate $\tau_{\text {coarse }}$ to be within the range 0.01 to 0.06 . Thus, Harvey's calculation, based on a control model $\tau$ of 0.13 , should be considered as an extreme upper limit of the climatic forcing due to ice-age dust and sea salt. Because Harvey's estimated LGM cooling of $2-3 \mathrm{~K}$ is simply proportional to the value of $\tau$ used in his control model, it should be reduced by a factor of at least two and possibly ten.

T. L. ANDERSON

R. J. CHARLSON

\section{Department of Atmospheric}

\section{Sciences,}

University of Washington,

Seattle,

Washington 98195, USA

1. Harvey, L. D. Nature 334, 333-335 (1988)

2. Legrand, M. R., Delmas, R. J. \& Charlson, R. J. Nature 334 $418-420$ (1988)

. Jaenicke, R. J. aerosol Sci. 11, 577-588 (1980)

. Whitby, K. T. Atmos. Envir. 12, 135-159 (1978)

. Clarke, A. D., Ahlquist, N. C. \& Covert, D. S. J. geophys Res. 92, 4179-4190 (1987).

6. Willeke, K. \& Brockmann, J. E. Atmos. Envir. 11, 995-999 (1977)

7. Toon, O. B.\& Pollack, J. B. J. appl. Meteorol. 15, 225-246 (1978)

\title{
Chance marsupial relationships
}

SIR-Thomas et al. ${ }^{1}$ interpret their evolutionary tree, based on $12 \mathrm{~S}$ ribosomal RNA gene sequence data for the marsupial wolf (Thylacinus cynocephalus) and six other marsupials, as evidence that the thylacine does not lie outside the Australian cluster of marsupial lineages. The strength of this evidence depends on the confidence we can have in their tree topology (their Fig. 2), but a comparison of the cladistic analysis of the observed $12 \mathrm{~S}$ ribosomal RNA data with similar randomized data sets suggests that their tree is not significantly different in its degree of cladistic structure, from cladograms produced 'by chance alone'.

The length of a cladogram (the smallest number of character state changes implied by the tree of minimum length) is a measure of cladistic structure. It reflects the extent to which co-variation of the characters allows hypotheses of common ancestry, as represented by sister-group

relations in the cladogram, to explain shared character states among the taxa ${ }^{2.3}$. Because cladistic algorithms will impose some cladistic structure even on data consisting of random numbers, it is informative to ask whether a given data set has more cladistic structure than would be expected by chance.
The original cladistic structure can be compared to the structure revealed by artificial data sets in which each original character is taken in turn and its observed character states are randomly reassigned, without replacement, to the taxa. A Monte Carlo study (repeated computer simulations using random numbers) compares the observed data to many such randomized sets.

The Monte Carlo test for the $12 \mathrm{~S}$ ribosomal RNA data focuses on the relationship of thylacines to other accepted monophyletic groups of marsupials. The two taxa in the Dasyuridae and the two in Phalangeridae are each combined into a single family-level taxon, to avoid testing for structure in the data due simply to the monophyly of these groups. Thus, five marsupial taxa are included in the data set. Because the outgroup status of Philander (Didelphidae) is well supported ${ }^{+}$, its character states are held constant; it is used as an outgroup taxon in the analysis of the randomized sets.

Characters (ribosomal RNA sites) that are invariant or which differ by a single character state among the five taxa are ignored; these will contribute constant amounts of character change over all data sets, and will not affect the results of the test. The reduced data set therefore has seven phylogenetically informative characters for the five taxa (see table). Cladistic analysis recovers the same topological relationships between the five families as reported by Thomas et al.; the tree has nine steps.

One of the randomized data sets from the Monte Carlo study is also shown in the table (data in parentheses and bold type). From a total of 99 randomized sets, a tree of the same length as, or shorter than, that of Thomas et al. is found nine times. A rough estimate of the significance is the proportion of all trees (including the original) having nine steps or fewer, that is 0.10 .

The results of this Monte Carlo test are surprising. They imply that if the $12 \mathrm{~S}$ ribosomal RNA nucleotides at each of the seven sites had been randomly assigned to taxa, there would have been a reasonable chance (about 1 in 10) that the cladogram produced would have had as much struc-
CHARACTER STATES AT PHYLOGENETICALLY INFORMATIVE SITES

\begin{tabular}{lrrrrrrr}
\hline Taxon & & & \multicolumn{7}{c}{ Site } & & \\
& 1 & 2 & 3 & 4 & 5 & 6 & 7 \\
Didelphidae & $\mathrm{G}(\mathbf{G})$ & $\mathrm{C}(\mathbf{C})$ & $\mathrm{C}(\mathbf{C})$ & $\mathrm{T}(\mathbf{T})$ & $\mathrm{A}(\mathbf{A})$ & $\mathrm{C}(\mathbf{C})$ & $\mathrm{C}(\mathbf{C})$ \\
Thylacinidae & $\mathrm{A}(\mathbf{A})$ & $\mathrm{C}(\mathbf{C})$ & $\mathrm{T}(\mathbf{T})$ & $\mathrm{A}(\mathbf{T})$ & $\mathrm{A}(\mathbf{T})$ & $\mathrm{T}(\mathbf{C})$ & $\mathrm{T}(\mathbf{C})$ \\
Dasyuridae & $\mathrm{G}, \mathbf{A}(\mathbf{A})$ & $\mathrm{C}(\mathbf{A})$ & $\mathrm{T}(\mathbf{T})$ & $\mathrm{A}(\mathbf{T})$ & $\mathrm{A}(\mathbf{T})$ & $\mathrm{T}(\mathbf{T})$ & $\mathrm{T}(\mathbf{T})$ \\
Peramelidae & $\mathrm{G}(\mathbf{G})$ & $\mathrm{A}(\mathbf{A}, \mathbf{T})$ & $\mathrm{C}(\mathbf{T})$ & $\mathrm{T}(\mathbf{A})$ & $\mathrm{T}(\mathbf{A})$ & $\mathrm{C}(\mathbf{C})$ & $\mathrm{C}(\mathbf{T})$ \\
Phalangeridae & $\mathrm{A}(\mathbf{G}, \mathbf{A})$ & $\mathrm{A}, \mathrm{T}(\mathbf{C})$ & $\mathrm{T}(\mathbf{C})$ & $\mathrm{T}(\mathbf{A})$ & $\mathrm{T}(\mathbf{A})$ & $\mathrm{C}(\mathbf{T})$ & $\mathrm{C}(\mathbf{C})$
\end{tabular}

Nucleotides at each of the seven informative sites (results of a Monte Carlo simulation in parentheses and bold type). For two of the sites in each array, one of the taxa is assigned two different nucleotides. The necessary extra character state change within the taxon is ignored in calculating tree length. The taxon assigned 'A, T' at site 2 is parsimoniously interpreted as having ancestral state ' $A$ ', and that assigned ' $G, A$ ' at site 1 as having that ancestral state implying the smallest number of character state changes for a given tree. 